\title{
Tip 2 Diyabetli Hastaların Beslenme Alışkanlıkları, Diyet Kalitesi ve Yeme Davranışlarının Değerlendirilmesi
}

\author{
DOI: $10.26466 /$ opus.857147
}

\author{
* \\ Elif Kaynarpunar * - Mehmet Akman ** \\ * Uzm. Dyt., Kocaeli Darıca Farabi Eğitim ve Araştırma Hastanesi, Kocaeli/Türkiye \\ E-Posta: elifsu92@hotmail.com \\ ORCID: 0000-0002-5899-4613 \\ ** Dr. Öğr. Üyesi, Beykent Üniversitesi Sağlık Bilimleri Yüksekokulu, İstanbul/Türkiye \\ E-Posta: mehmetakman@beykent.edu.tr O ORCID: 0000-0001-9995-4426
}

Öz

Diyabet, Türkiye'de prevalansı oldukça yüksek olan, mortalite ve morbiditeyi arttıran kronik metabolik bir hastalıktır. Kan şekeri kontrolünün sağlanmasında ve diyabetin neden olabileceği komplikasyonların önlenmesinde doğru beslenme alışkanlıkları ve diyet kalitesinin yüksek olması çok önemlidir. Bu çalışma tip 2 diyabetli bireylerin beslenme alı̧̧kanlıklarl, diyet kalitesi ve yeme davranışlarım belirlemek amacıyla yapılmıştır. Çalışmaya Tip 2 diyabet tanısı almış 202 birey katılmıştır. Bireylerin; demografik özellikleri, beslenme alışkanlıkları bir anket formu ile sorgulanmış, ağırlıkları ve boy uzunlukları ölçülmüş, 3 günlük besin tüketim kaydı alınmış ve Hollanda Yeme Davranışı Anketi (DEBQ) uygulanmıştır. Kadın bireylerin günlük ortalama $1522.4 \pm 332.19$ kkal., erkeklerin ise $1846.4 \pm 373.22 \mathrm{kkal}$. aldığ 1 hesaplanmıştır. Să̆lıklı Yeme İndeksi puanı tüm bireylerde ortalama $63.77 \pm 10.93$ bulunmuştur. Tüketilen besin çeşidi sayısı ortalaması açısından kadınlar ile erkekler arasında istatistiksel olarak önemli farklilık bulunmamaktadır ( $p<0,05)$. Kadınların kısıtlayıcı yeme skoru ortalaması ve duygusal yeme skoru ortalaması erkeklerin kısıtlayıcı yeme skoru ortalaması ve duygusal yeme skoru ortalamasindan istatistiksel olarak anlaml düzeyde fazladır ( $p<0.05$ ). Diyabetli hastalarda glisemik kontrolün sağlanması, komplikasyonları önlenmesi için yeme bozuklukları ve beslenme alışkanlıkları düzeltilmelidir.

Anahtar Kelimeler: $\quad$ tip 2 diyabet, diyet kalitesi, beslenme alışkanlığı, yeme davranışı 


\title{
Determination of Nutritional Habits, Diet Quality and Eating Behaviors of Patients with Type 2 Diabetes
}

\begin{abstract}
Diabetes prevalence in Turkey is quite high, it is a chronic metabolic disease which increases the mortality and morbidity. Correct eating habits and high dietary quality are important in ensuring blood sugar control and preventing complications that may be caused by diabetes. This study was conducted to determine the dietary habits, diet quality and eating behaviors. Sample was consisted of 202 patients who were diagnosed as Type 2 diabetes. Demographic characteristics, nutritional habits of individuals were questioned by a questionnaire, weight and length were measured, 3 days of food consumption was recorded, Dutch Eating Behavior Questionnaire (DEBQ) was applied. It was calculated that female individuals received an average of $1522.4 \mathrm{kcal}$ per day and male individuals received $1846.4 \mathrm{kcal}$. The mean score of healthy eating index was $63.77 \pm 10.93$ in all participants. There is no statistically significant difference between males and females in terms of the average number of consumed food variety. The restrictive and emotional eating score of women was significantly higher than that of males' statistically $(p<0.05)$. Eating disorders and nutritional habits should be corrected in patients with diabetes to ensure glycemic control and prevent complications.
\end{abstract}

Keywords: type 2 diabetes, diet quality, eating habits, eating behavior. 


\section{Giriş}

Diyabet, insülin salgilanmasında, aktivitesinde veya her ikisinde birden oluşan bozukluktan kaynaklanan hiperglisemi ile görülen metabolik bir hastaliktır (American Diabetes Association, 2014, s.37). Uluslararası Diyabet Federasyonu (IDF), 2009 yılında 285 milyon olan diyabet hasta sayısının (tip 1 ve tip 2) 2017'de 425 milyona yükseldiğini bildirmekte ve 2045 yılında bu sayının 628.6 milyona ulaşacağını tahmin etmektedir (International Diabetes Federation, 2017; Saeedi,vd., 2019, s.157).

Tip 1 diyabet, tip 2 diyabet ve gestasyonel diyabet olmak üzere 3 ana tip diyabet türü vardır (Saeedi,vd., 2019, s.157). Tip 2 Diabetes Mellitus (Tip 2 DM), hiperglisemi, insülin direnci ve göreli insülin eksikliği ile karakterize DM'nin en yaygın şeklidir. 1936 yılında İngiltere'de Sir Himsworth insülin duyarlılığından ilk kez bahsetmiştir. Böylelikle tip 1 ve tip 2 diyabet kavramlarının ayrımı yapılmaya başlanmıştır (AB. Olokoba, Obateru ve LB. Olokoba, 2012, s.27). Tip 2 diyabet tüm dünyada en yaygin görülen diyabet tipi olmasının yanında diyabetik ketoasidoz, hipoglisemi nedenli koma gibi akut metabolik komplikasyonlara, uzun dönemde meydana gelen makrovasküler komplikasyonlara (koroner kalp hastalığı, periferik damar hastalığı, serebrovasküler hastalık) ve mikrovasküler komplikasyonlara (nöropati, nefropati, retinopati) neden olması dolayısıyla önemli kronik metabolik bir hastalıktır (Forbes ve Cooper, 2013, s.93; Özdemir ve Hocaoğlu, 2009, s.24). Wu, Ding, Tanaka ve Zhang (2014)'a göre tip 2 DM'li hastalar genellikle eksojen insüline ihtiyaç duymamakla birlikte, kan şekeri düzeyleri tek başına, oral hipoglisemik ilaçlarla ya da diyetle iyi kontrol edilmediğinde gerekli olabilmektedir. Diyabet ve diyet arasındaki bağlantı kanıtlanmıştır, diyabet tedavisinde diyet tıbbi müdahalelerle kadar önemlidir (Morris ve Wylie-Rosett, 2010, s.28). Diyet, diyabetli hastalarda glisemik kontrolün sağlanması, mikro ve makrovasküler komplikasyonların önlenmesine yönelik terapötik stratejide önemli bir rol oynamaktadır (Rivellese vd., 2008, s.62). Ayrıca her 1 kilogram ağırlık kazanımının diyabet riskini $\% 9$, her 1 kilogram ağılık kaybının riski \%5 azalttığı ve glisemik kontrolü iyileştirdiği tahmin edilmektedir (Morris vd., 2018, s.9). Diyabetli bireyler hayat boyu kan şekerlerini kontrol altında tutabilmek için beslenme alışkanlıklarını ve yaşam tarzlarını düzenlemek zorundadır. Hastalığın kontrolü için, uyulması gereken diyet listeleri, yasaklanan yiye- 
cekler ve kronik bir hastalık olması gibi faktörler hastalarda anksiyeteye neden olmakta, zihnin yiyeceklerle ve ağırlık kontrolüyle meşgul olmasına yol açmaktadır. Bu nedenlerden dolayı da hastaların yeme tutum ve davranışlarında bozulmalar görülebilmektedir (Z. Çobanoğlu, Altuntaş, Karamustafalıŏlu, Şengül ve N. Çobanoğlu, 2008, s.21).

Bu çalışmanın amacı tip 2 diyabetli hastaların beslenme alışkanlıkları, diyet kalitesi ve yeme davranışlarının belirleyerek daha sonra yapılacak çalışmalara katkı sağlamaktır.

\section{Yöntem}

\section{Araştırmanın evren ve örneklemi}

Araştırmanın evrenini 01.Nisan/30.Haziran.2018 tarihleri arasında Kocaeli Darıca Farabi Eğitim ve Araştırma Hastanesi, Beslenme ve Diyet Polikliniğine başvuran, daha önce tip 2 diyabet tanısı almış kişiler oluşturmuştur. Örneklem sayısı; 2017 yılında Kocaeli Darıca Farabi Eğitim ve Araştırma Hastanesi Beslenme ve Diyet Polikliniğine başvuran tip 2 diyabet tanısı almış 423 hasta sayısı baz alınarak \%95 güven aralığında 202 olarak hesaplanmıştır. Örneklem yöntemi olarak sistematik örnekleme seçilmiştir.

\section{Veri toplama araçları}

Araştırmaya katılan bireylere yüz yüze görüşme yöntemiyle; araştırmacı tarafından hazırlanmış anket formu ve Hollanda Yeme Davranışı Anketi (DEBQ) ve Besin Çeşitliliği Skoru ile Sağlıklı Yeme İndeksi-2005 (SYİ) uygulanmıştır. Ayrıca "3 günlük besin tüketim formu" ile bir gün hafta sonu iki gün hafta içi olmak üzere toplam üç günlük 24 saatlik besin tüketim kaydı alınmıştır. Porsiyon ölçüleri belirlenirken "Resimli Fotoğraf Kataloğu" ve besin replika modellerinden yararlanılmıştır (Rakıcıoğlu, Tek, Ayaz ve Pekcan, 2012). Bireylerden alınan besin tüketim kayıtlarına göre Besin Çeşitliliği Skoru ve SYİ kullanılarak sağlıklı yeme indeksi hesaplanmıştır. Bireylerin vücut ağırlığı Tanita BC 418 marka cihaz ile hafif giysili ve ayakkabısız olarak ölçülmüştür. 
Anket formu; 1.bölümünde kişilere ait genel özellikleri (yaş, meslek vb.)(14 soru), 2.bölümünde ise kişilerin beslenme alışkanlıklarını saptamaya yönelik (22 soru) sorudan oluşmaktadır.

DEBQ ise; duygusal yeme davranışlarını (örneğin; biri sizi üzdüğünde yemek ister misiniz?), dışsal yeme davranışlarını (yediğiniz şeyin kokusu çok güzelse, normalde yediğinizden fazla yer misiniz?) ve kısıtlayıc yeme davranışlarını (çok fazla yediğinizde, ertesi gün daha az yer misiniz?) ölçen 3 alt ölçekten meydana gelen, 33 maddeden oluşan bir ölçektir.

\section{Verilerin istatistiksel değerlendirilmesi}

Araştırma sonucunda elde edilen veriler SPSS (Statistical Package for Social Sciences) 15.0 İstatistiksel paket programı kullanılarak analiz edilmiştir. Bireylerin günlük diyetle aldıkları enerji ve besin ögelerinin değerlendirilmesinde Beslenme Bilgi Sistemi (BeBİS) 7.1 bilgisayar paket programı kullanılmıştır (Erhardt, 2010).

Nitel değişkenler sayı (S) ve yüzde (\%) olarak, nicel değişkenler ise ortalama, standart sapma (SS), alt ve üst değerler olarak ifade edilmiştir. Nicel (ölçüm) verilerin normal dağılıma uygunluğu "Kolmogorov-Smirnov Testi" ile incelenmiştir. İki grubun karşılaştırılması amacıyla parametrik test koşullarının sağlandığı nicel değişkenler için "bağımsız gruplarda t testi- student $t$ testi" , parametrik test koşulları sağlanmadığı değişkenler için "Mann Whitney U" testi kullanılmıştır. Üç ve üzeri grupların karşılaştırmalarında ise nicel değişkenler için parametrik test koşulları sağlanmadığı değişkenler için "Kruskal Wallis Test" kullanılmıştır. Niteliksel verilerin karşılaştırılmasında ise "Pearson Ki-Kare testi" kullanılmıştır. Parametreler arası ilişkilerin değerlendirilmesinde de "Spearman's Korelasyon Analizi" kullanılmıştır. Anlamlılık $\mathrm{p}<0,05$ düzeyinde, güven aralığı $\% 95$ olarak kabul edilip değerlendirilmiştir.

\section{Bulgular}

Araştırmaya 124'ü (\%61.4) kadın, 78'i (\%38.6) erkek olmak üzere 202 hasta katılmıştır. Hastaların \%63.4'ü fazla kiloludur (BKİ 25.0-29.9). Hastaların 
\%67.3'ünde birinci derece akrabalarında diyabet hastalığı bulunmaktadır. Bireylerin tip 2 diyabet hastası olma süresi ortalama 5.33 yıldır. Hastaların $\% 57.9^{\prime} \mathrm{u}$ oral anti-diyabetik tedavi yöntemini kullanmaktadır.

Bireylerin \%59.4'ünün beslenme alışkanlıklarında diyabet hastası olduğunu öğrendikten sonra değişiklik olmuştur. Ve \%55.4'ü yemeklerini belirli saatlerde yemektedir. Katılımcların \%57.4'ü günde 2 ana öğün tüketmektedir. Ana öğün atlama sıklığına baktı̆̆ımızda; \%14.9'u hiç ana öğün atlamamakta, \%31.7'si nadiren, \%36.6'sı arada bir, \%16.8'i sık sık ana öğün atlamaktadır. En çok atlanan ana öğün öğle öğünüdür. Ayrıca katılımcların \%95.5'i ara öğün atladığını belirtmiştir.

Ev dışında yemek yeme sıklığına bakıldığında, katılımcıların \%4'ünün her gün, \%27.7'sinin ayda 2-3 kez, \%24.8' inin 2-3 ayda bir ev dışında yemek yediği, \%7.9'unun ise ev dışında hiç yemek yemediği görülmüştür. Bireyler ev dişında yemek için en çok kebap türü yiyecekleri tercih etmektedir.

Araştırmaya katılan bireylerin \%55.4'ünün yemeklerine tuz ilave etmediklerini belirtmelerine rağmen, diyetle alınan sodyum miktarlarına bakıld1ğında tavsiye edilen günlük sodyum miktarının aşıldığı görülmektedir.

Katılımcıların yemeklerinde en çok tercih ettikleri yağ türü zeytinyağı (\%45), en çok tükettikleri ekmek çeşidi beyaz ekmek (\%57.9), en çok kullandıkları pişirme yöntemi haşlamadır (\%37.1).

Bireylerin cinsiyete göre diyetle alınan 3 günlük enerji ve besin ögesi ortalamaları Tablo 1'de verilmiştir. Kadınların diyetle 1522.4 \pm 332.19 kkal, erkeklerin ise $1846.4 \pm 373.22 \mathrm{kkal}$ aldıkları saptanmıştır ve aralarındaki fark istatistiksel olarak önemli bulunmuştur $(\mathrm{p}<0.05)$. Günlük alınan enerjinin $\% 44.6 \pm 5.6$ 'sinın karbonhidratlardan $(\mathrm{CHO}), \% 17.1 \pm 2.4$ ünün proteinlerden, \%38.1 $\pm 4.9^{\prime}$ unun da yağlardan geldiği saptanmıştır. Tüketilen doymuş yağ

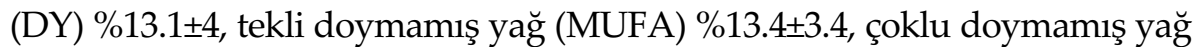
(PUFA) \%9 2.3 olarak belirlenmiştir. Günlük ortalama posa tüketim miktarı ise 22.3 gramdır. Cinsiyete göre CHO (\%), Yağ (\%), DYA(\%), MUFA(\%), PUFA(\%) ve posa tüketim düzeyleri istatistiksel olarak anlamlı farklılık göstermektedir $(\mathrm{p}<0.05)$. Erkeklerin günlük tükettikleri ortalama $\mathrm{CHO}(\%)$, ve posa miktarı kadınların günlük tükettiği ortalama, $\mathrm{CHO}(\%)$ ve posa miktarından istatistiksel olarak anlamlı düzeyde fazla olmasına karşın; yağ(\%), DYA(\%), MUFA(\%) ve PUFA(\%) istatistiksel olarak anlamlı düzeyde azdır. Cinsiyete göre protein(\%) ortalama tüketim düzeyleri arasında istatistiksel olarak anlamlı farklılık bulunmamaktadır ( $\mathrm{p}>0.05)$. 
SYİ puanı kadınlarda $67.64 \pm 11.27$, erkeklerde $57.72 \pm 10.39$ bulunmuştur. Kadınların SYİ puan ortalaması, erkeklerin SYİ puan ortalamasından istatistiksel olarak önemli düzeyde yüksektir $(\mathrm{p}<0.05)$ (Tablo 2).

Tablo 1. Bireylerin günlük tükettikleri enerji ve makro besin ögeleri

\begin{tabular}{|c|c|c|c|c|c|c|c|c|c|c|}
\hline \multirow{2}{*}{$\begin{array}{l}\text { Enerji ve } \\
\text { besin öge- } \\
\text { leri }\end{array}$} & \multicolumn{3}{|l|}{$\begin{array}{l}\text { Kadın } \\
\text { (124) }\end{array}$} & \multicolumn{3}{|l|}{$\begin{array}{l}\text { Erkek } \\
\text { (78) }\end{array}$} & \multirow[t]{2}{*}{$\mathbf{P}$} & \multicolumn{3}{|c|}{$\begin{array}{l}\text { Toplam } \\
\text { (202) }\end{array}$} \\
\hline & Ort & SS & $\begin{array}{l}\text { Alt- } \\
\text { üst }\end{array}$ & Ort & SS & $\begin{array}{l}\text { Alt- } \\
\text { üst }\end{array}$ & & Ort & SS & $\begin{array}{l}\text { Alt- } \\
\text { üst }\end{array}$ \\
\hline Enerji(kkal) & 1522.4 & 332.19 & $\begin{array}{l}475.8- \\
2436.8\end{array}$ & 1846.4 & 373.22 & $\begin{array}{l}1100.2- \\
2841.7\end{array}$ & ${ }^{a} 0.000^{*}$ & 1647.3 & 381.66 & $\begin{array}{l}475.8- \\
2841.7\end{array}$ \\
\hline $\mathrm{CHO}(\mathrm{g})$ & 161.8 & 43.75 & $\begin{array}{l}46.4- \\
284.2\end{array}$ & 211.6 & 51.50 & $\begin{array}{l}108.1- \\
352.2\end{array}$ & ${ }^{a} 0.000^{*}$ & 181.1 & 52.73 & $\begin{array}{l}46.4- \\
352.2\end{array}$ \\
\hline $\mathrm{CHO}(\%)$ & 43.2 & 5.73 & $\begin{array}{l}26.0- \\
56.0\end{array}$ & 46.7 & 4.91 & $\begin{array}{l}34.0- \\
56.0\end{array}$ & ${ }^{a} 0.000^{*}$ & 44.6 & 5.67 & $\begin{array}{l}26.0- \\
56.0\end{array}$ \\
\hline Protein(g) & 63.6 & 14.65 & $\begin{array}{l}18.7- \\
121.3\end{array}$ & 76.2 & 15.66 & $\begin{array}{l}44.8- \\
112.9\end{array}$ & ${ }^{b} 0.000^{*}$ & 68.5 & 16.23 & $\begin{array}{l}18.7- \\
121.3\end{array}$ \\
\hline Protein(\%) & 17.2 & 2.55 & $\begin{array}{l}12.0- \\
24.0\end{array}$ & 16.9 & 2.22 & $\begin{array}{l}11.0- \\
23.0\end{array}$ & ${ }^{a} 0.528$ & 17.1 & 2.42 & $\begin{array}{l}11.0- \\
24.0\end{array}$ \\
\hline Yağ(g) & 67.3 & 16.73 & $\begin{array}{l}23.2- \\
113.4\end{array}$ & 74.7 & 16.76 & $\begin{array}{l}40.3- \\
117.6\end{array}$ & ${ }^{a} 0.003^{*}$ & 70.1 & 17.18 & $\begin{array}{l}23.2- \\
117.6\end{array}$ \\
\hline Yağ(\%) & 39.4 & 4.93 & $\begin{array}{l}28.0- \\
54.0\end{array}$ & 36.1 & 4.17 & $\begin{array}{l}26.0- \\
44.0\end{array}$ & ${ }^{a} 0.000^{*}$ & 38.1 & 4.92 & $\begin{array}{l}26.0- \\
54.0\end{array}$ \\
\hline DYA(\%) & 13.7 & 4.09 & $\begin{array}{l}4.5- \\
26.3\end{array}$ & 12.3 & 3.96 & $\begin{array}{l}6.3- \\
18.5\end{array}$ & ${ }^{a} 0.013^{*}$ & 13.1 & 4.07 & $\begin{array}{l}4.5- \\
26.3\end{array}$ \\
\hline MUFA(\%) & 14.1 & 3.51 & $\begin{array}{l}4.3- \\
25.2\end{array}$ & 12.4 & 3.28 & $\begin{array}{l}7.1- \\
21.1\end{array}$ & ${ }^{a} 0.011^{*}$ & 13.4 & 3.41 & $\begin{array}{l}4.3- \\
25.2\end{array}$ \\
\hline PUFA(\%) & 9.0 & 2.34 & $\begin{array}{l}2.7- \\
22.6\end{array}$ & 8.9 & 2.27 & $\begin{array}{l}2.7- \\
17.7\end{array}$ & ${ }^{b} 0.001^{*}$ & 9.0 & 2.31 & $\begin{array}{l}2.7- \\
22.6\end{array}$ \\
\hline Posa(g) & 20.6 & 4.96 & $\begin{array}{l}6.23- \\
34.2\end{array}$ & 24.9 & 5.76 & $\begin{array}{l}13.7- \\
38.4\end{array}$ & ${ }^{a} 0.000^{*}$ & 22.3 & 5.68 & $\begin{array}{l}6.23- \\
38.4\end{array}$ \\
\hline
\end{tabular}

aStudent $t$ test, ${ }^{b}$ MannWhitney $U$ test

${ }^{*} p<0.05$

Tablo 4'te bireylerin DEBQ yeme skorlarının cinsiyete göre dağılımı gösterilmiştir, Kadınların kısıtlayıcı yeme skoru ortalaması 2.72 \pm 0.72 iken erkek-

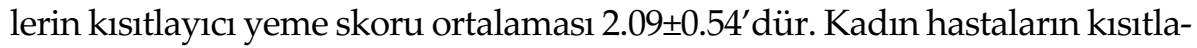
yıc yeme skoru erkek hastaların kısıtlayıcı yeme skorundan istatistiksel olarak önemli düzeyde fazladır ( $\mathrm{p}=0.000 ; \mathrm{p}<0.05$ ). Kadınların duygusal yeme skoru ortalaması $2.37 \pm 0.71$, erkeklerin duygusal yeme skoru ortalaması $1.72 \pm 0.65$ 'dir. Kadınların duygusal yeme skoru ile erkeklerin duygusal yeme skorları arasında istatistiksel olarak önemli farklılık bulunmamıştır ( $\mathrm{p}=0.000$; $\mathrm{p}>0.05)$; kadın hastaların duygusal yeme skoru erkek hastaların duygusal yeme skorundan önemli düzeyde fazladır. Kadınların ve erkeklerin dışsal 
yeme skoru ortalamaları sırasıyla $2.65 \pm 0.53$ ve $2.66 \pm 0.50$ 'dir. Kadınların dışsal yeme skoru ile erkeklerin dişsal yeme skorları arasında istatistiksel olarak önemli farklılık bulunmamıştır ( $\mathrm{p}>0.05)$.

Tablo 2. Bireylerin cinsiyete göre SYI puanlar

\begin{tabular}{|c|c|c|c|c|}
\hline & Kadın & Erkek & Toplam & $p$ \\
\hline SYİ puanları & $\mathrm{X} \pm \mathrm{SS}$ & $X \pm S S$ & $X \pm S S$ & \\
\hline Toplam meyve (0-5) & $3.46 \pm 2.04$ & $2.37 \pm 1.96$ & $3.03 \pm 2.0$ & ${ }^{b} 0.000^{*}$ \\
\hline Tam meyve (0-5) & $3.81 \pm 2.12$ & $2.63 \pm 1.89$ & $3.35 \pm 2.03$ & ${ }^{b} 0.000^{*}$ \\
\hline Toplam sebze (0-5) & $4.16 \pm 1.88$ & $2.74 \pm 2.01$ & $3.61 \pm 1.93$ & ${ }^{b} 0.000^{*}$ \\
\hline \multicolumn{5}{|l|}{ Koyu Yeşil ve } \\
\hline Turuncu Sebzeler (0- & & & $2.70 \pm 2.11$ & ${ }^{b} 0.000^{*}$ \\
\hline 5) & $3.04+2.23$ & $2.16 \pm 1.92$ & & \\
\hline Toplam tahıl (0-5) & $4.57 \pm 1.48$ & $4.63 \pm 1.53$ & $4.59 \pm 1.50$ & ${ }^{b} 0.102$ \\
\hline Tam tahıl (0-5) & $2.04 \pm 1.98$ & $1.76 \pm 1.65$ & $1.93 \pm 1.85$ & ${ }^{b} 0.013^{*}$ \\
\hline Süt grubu (0-10) & $5.16 \pm 1.02$ & $4.02 \pm 1.74$ & $4.72 \pm 1.30$ & ${ }^{b} 0.000^{*}$ \\
\hline $\begin{array}{l}\text { Et ve Kuru baklagil- } \\
\text { ler }(0-10)\end{array}$ & $6.72+2.46$ & $7.10 \pm 3.15$ & $6.87 \pm 2.73$ & ${ }^{b} 0.003^{*}$ \\
\hline Yağ grubu (0-10) & $7.98 \pm 2.89$ & $7.37 \pm 2.03$ & $7.74+2.56$ & ${ }^{b} 0.011^{*}$ \\
\hline Doymuş yağ (0-10) & $4.38 \pm 3.01$ & $4.43 \pm 2.75$ & $4.39 \pm 2.91$ & ${ }^{b} 0.080$ \\
\hline Sodyum (0-10) & $3.86 \pm 2.04$ & $2.14 \pm 2.26$ & $3.19 \pm 2.12$ & ${ }^{b} 0.000^{*}$ \\
\hline $\begin{array}{l}\text { Doymuş yağ - rafine } \\
\text { şeker - alkolden ge- } \\
\text { len enerji (0-20) }\end{array}$ & $18.46 \pm 1.06$ & $16.37 \pm 1.84$ & $17.65 \pm 1.36$ & ${ }^{b} 0.000^{*}$ \\
\hline $\begin{array}{l}\text { Toplam SYİ puanı (0- } \\
\text { 100) }\end{array}$ & $67.64 \pm 11.27$ & $57.72 \pm 10.39$ & $63.77 \pm 10.93$ & ${ }^{b} 0.000^{*}$ \\
\hline
\end{tabular}

${ }^{b}$ MannWhitney $U$ test ${ }^{*} p<0.05$

Çalışmaya katılan bireylerin tükettikleri 3 günlük besin çeşidi ortalamaları cinsiyete göre incelendiğinde; kadınların tükettiği besin çeşidi ortalaması $9.05 \pm 1.49$, erkeklerin tükettiği besin çeşidi ortalaması $9.12 \pm 1.24$ 'dür. Besin çeşidi sayısı ortalaması açısından kadınlar ile erkekler arasında istatiksel olarak önemli farklılık bulunmamaktadır ( $>>0.05$ ) (Tablo 3).

Tablo 3. Bireylerin tükettikleri ortalama besin çeşidi sayısı

\begin{tabular}{llllllllllll}
\hline & \multicolumn{1}{c}{ Kadın } & \multicolumn{9}{c}{ Erkek } & \multicolumn{3}{c}{ Toplam } & \multicolumn{1}{c}{$p$} \\
\cline { 2 - 10 } & $X$ & SS & Alt-Üst & $X$ & SS & $\begin{array}{c}\text { Alt- } \\
\text { Üst }\end{array}$ & $X$ & SS & $\begin{array}{c}\text { Alt- } \\
\text { Üst }\end{array}$ & \\
\hline $\begin{array}{l}\text { Besin } \\
\text { çeşidi } \\
\text { sayisı }\end{array}$ & 9.05 & 1.49 & $5-12$ & 9.12 & 1.24 & $5-12$ & 9.08 & 1.39 & $5-12$ & ${ }^{b 0.854}$ \\
\hline
\end{tabular}

${ }^{b}$ Mann Whitney U test 
Tip 2 Diyabetli Hastaların Beslenme Alışkanlıkları, Diyet Kalitesi ve Yeme Davranışlarının Değerlendirilmesi

Tablo 4. Bireylerin DEBQ yeme skorlarn

\begin{tabular}{|c|c|c|c|c|c|c|c|c|c|c|}
\hline & \multicolumn{2}{|c|}{ Kadın } & \multicolumn{3}{|c|}{ Erkek } & \multicolumn{4}{|c|}{ Toplam } & \multirow[t]{2}{*}{$p$} \\
\hline & $x$ & SS & $\begin{array}{l}\text { Alt- } \\
\text { Üst }\end{array}$ & $x$ & SS & $\begin{array}{l}\text { Alt- } \\
\text { Üst }\end{array}$ & $x$ & SS & $\begin{array}{l}\text { Alt- } \\
\text { Üst }\end{array}$ & \\
\hline $\begin{array}{l}\text { Kisitlayıcı } \\
\text { yeme skoru }\end{array}$ & 2.72 & 0.72 & $\begin{array}{l}1.0- \\
4.5\end{array}$ & 2.09 & 0.54 & $\begin{array}{l}1.0- \\
3.4\end{array}$ & 2.48 & 0.72 & $\begin{array}{l}1.0- \\
4.5\end{array}$ & ${ }^{b} 0.000^{*}$ \\
\hline $\begin{array}{l}\text { Duygusal } \\
\text { yeme skoru }\end{array}$ & 2.37 & 0.71 & $\begin{array}{l}1.0- \\
4.76\end{array}$ & 1.72 & 0.65 & $\begin{array}{l}1.0- \\
3.76\end{array}$ & 2.12 & 0.75 & $\begin{array}{l}1.0- \\
4.76\end{array}$ & ${ }^{b} 0.000^{*}$ \\
\hline $\begin{array}{l}\text { Dişsal yeme } \\
\text { skoru }\end{array}$ & 2.65 & 0.53 & $\begin{array}{l}1.6- \\
4.3 \\
\end{array}$ & 2.68 & 0.47 & $\begin{array}{l}1.5- \\
4.0\end{array}$ & 2.66 & 0.50 & $\begin{array}{l}1.5- \\
4.3\end{array}$ & ${ }^{b} 0.749$ \\
\hline
\end{tabular}

${ }^{b}$ Mann Whitney U test $\quad * p<0.05$

BKİ gruplarına göre DEBQ kısıtlayıc yeme skoru değerlendirilmesine bakıldığında; DEBQ kısıtlayıcı yeme skoru ortalaması; BKİ'si $18.5-24.9$ kg/m² olan bireylerde $2.71 \pm 1.03$. $25.0-29.9 \mathrm{~kg} / \mathrm{m}^{2}$ olan bireylerde $2.48 \pm 0.69,30.0-34.9$ $\mathrm{kg} / \mathrm{m}^{2}$ olan bireylerde $2.34 \pm 0.71,35.9-39.9 \mathrm{~kg} / \mathrm{m}^{2} 2.80 \pm 0.79,40.0$ ve üstü olan bireylerde $2.80 \pm 0.82$ olarak bulunmuştur. Bireylerin BKİ gruplarına göre DEBQ kısıtlayıc yeme skor ortalamaları arasında istatistiksel olarak anlamlı farklılık bulunmamıştır ( $\mathrm{p}>0.05)$. DEBQ duygusal yeme skoru ortalaması; BKİ'si $18.5-24.9 \mathrm{~kg} / \mathrm{m}^{2}$ olan bireylerde $2.54 \pm 0.92,25.0-29.9 \mathrm{~kg} / \mathrm{m}^{2}$ olan bireylerde $2.10 \pm 0.75,30.0-34.9 \mathrm{~kg} / \mathrm{m}^{2}$ olan bireylerde $2.06 \pm 0.76,35.9-39.9 \mathrm{~kg} / \mathrm{m}^{2}$ $2.25 \pm 0.54$. 40.0 ve üstü olan bireylerde $2.05 \pm 0.83$ olarak bulunmuştur. Bireylerin BKİ gruplarına göre DEBQ duygusal yeme skor ortalamaları arasında istatistiksel olarak anlamlı farklılık bulunmamıştır ( $p>0.05)$. DEBQ dışsal yeme skoru ortalamasi; BKİ'si 18.5-24.9 kg/m² olan bireylerde 2.81 $\pm 0.49,25.0-29.9$ $\mathrm{kg} / \mathrm{m}^{2}$ olan bireylerde $2.57 \pm 0.49,30.0-34.9 \mathrm{~kg} / \mathrm{m}^{2}$ olan bireylerde $2.83 \pm 0.46$, $35.9-39.9 \mathrm{~kg} / \mathrm{m}^{2} 2.71 \pm 0.59,40.0$ ve üstü olan bireylerde $3.10 \pm 0.75$ olarak bulunmuştur. Bireylerin BKİ gruplarına göre DEBQ dışsal yeme skor ortalamaları arasında istatistiksel olarak anlamlı düzeyde farklılık görülmektedir $(\mathrm{p}=0.017 ; \mathrm{p}<0.05)$. Farklılık yaratan grubun belirlenmesi amaciyla yapılan ikili karşılaştırmalara göre; BKİ'si 25.0-29.9 kg/m² olan bireylerin DEBQ dışsal yeme skoru BKİ'si 30.0-34.9 olan bireylerden istatistiksel olarak anlamlı düzeyde düşük bulunmuştur $(\mathrm{p}<0.05)$.

Tablo 5'te bireylerin kısıtlayıcı, dişsal ve duygusal yeme skorlarının kendi aralarındaki ilişkisi verilmiştir. Bireylerin DEBQ kısıtlayıcı skorları ile DEBQ dışsal skorları arasında istatistiksel olarak anlamlı ilişki bulunmamaktadır $(\mathrm{p}>0.05)$. 
Bireylerin DEBQ kısıtlayıc skorları ile duygusal skorları $(\mathrm{p}=0.000 ; \mathrm{p}<0.05)$ ve dışsal skorları ile duygusal skorları $(\mathrm{p}=0.000 ; \mathrm{p}<0.05)$ arasında pozitif yönlü (kısıtlayıcı skor arttıkça duygusal skor artan ve dışsal skor arttıkça duygusal skor artan) istatistiksel olarak anlamlı ilişki saptanmıştır.

Tablo 5. Bireylerin DEBQ alt skorlarının kendi arasındaki ilişkisi

\begin{tabular}{lllll}
\hline & $\begin{array}{l}\text { Duygusal skor } \\
\text { er }\end{array}$ & $\mathbf{p}$ & $\begin{array}{l}\text { Dişsal skor } \\
\text { er }\end{array}$ & $\mathbf{p}$ \\
\hline Kisitlayıcı skor & 0.361 & $0.000^{*}$ & 0.038 & 0.593 \\
Duygusal skor & - & - & 0.263 & $0.000^{*}$ \\
\hline${ }^{e}$ r: Spearman's Korelasyon Katsaylsi & ${ }^{*} p<0.05$ & &
\end{tabular}

\section{Tartışma ve Sonuç}

Diyabet, Türkiye'de prevalansı oldukça yüksek olan, mortalite ve morbiditeyi arttıran kronik metabolik bir hastalıktır. Kan şekeri kontrolünün sağlanmasında ve diyabetin neden olabileceği komplikasyonların önlenmesinde doğru beslenme alışkanlıkları ve diyet kalitesinin yüksek olması çok önemlidir. Kazanılması gereken beslenme alışkanlıklarından biri de ana ve ara ögünleri düzenli bir şekilde yapmaktır. Araştırmamıza katılan bireylerin \%14.9'unun ana öğün atlamadığı, \%31.7'sinin nadiren, \%36.6'sının arada bir, \%16.8' inin sık sık ana öğün atladığ1 ve en çok atlanan ana öğünün öğle öğünü (\%80.2) olduğu görülmüştür. Ayrıca bireylerin \%95.5' inin ara ögün atladığ ve en sık atlanan ara öğünün kuşluk ara öğünü (\%66.7) olduğu saptanmıştır. Obez, diyabetik, obez olmayan- diyabetik olmayan gruplar arasında yürütülen bir çalışmanın sonucuna göre, yapılan ana öğün, ara öğün sayısı, öğün atlama durumu ve genellikle atlanan ögünlere bakıldığında gruplar arasında istatistiksel olarak anlamlı düzeyde farklılıklar belirlenmiştir $(\mathrm{p}<0.05)$ (Baban, 2010). Genel olarak bütün grupların günde üç ana öğün tükettiği, ancak özellikle diyabetik grubun (\%92.6) üç ana-üç ara öğün yapmaya en çok dikkat eden grup olduğu gözlenmiştir ( $p<0.05)$. Baban (2010)'ın yaptı̆̆ı çalışmada üç ara öğün yapma oranı obez, diyabetik ve kontrol grubunda sirasiyla \%34, $\% 40, \% 21.2$ olarak görülmüştür.

Yapılan çalışmalar LDL-kolesterol seviyelerinin ve glukoz intoleransının, doymuş yağ asitlerinin doymamış yağ asitleri ile yer değiştirmesi ile düşürüldüğünü rapor etmektedir (Mann vd., 2004, s.14). Ayrıca Schwingshackl vd 
(2017)'nin 15784 tip 2 DM olgusu ile yaptığ bir meta analiz çalışmasında zeytinyağı takviyesi ile tip $2 \mathrm{DM}^{\prime}$ li hastalarda kontrol grubuna göre $\mathrm{HbA1c}$ 'de ve açlık plazma glikozunda belirgin şekilde bir azalma gözlemlenmiştir. Çalışmamıza katılan bireylerin kullandıkları yağ türleri incelendiğinde; bireylerin \%45' inin yemeklerde zeytinyağı, \%42.1'inin ayçiçeği yağı, \%3.5'inin mısırözü yağı, \%1.5' inin fındık yağı, \%7.4'ünün tereyağı ve \%0.5'inin de margarin kullandığını saptanmıştır.

Kanada'da yapılan bir çalışmaya göre, diyabet riskinin yağlı pişirme yöntemlerinin tercih edilmesiyle arttığ bulunmuştur (Baban, 2010). Bu araştırmada, en sık kullanılan yemek pişirme yöntemlerine bakıldığında, katılımc1ların en çok haşlama (\%37.1), ikinci olarak da kızartma (\%22.8) yöntemini kullandıkları saptanmıştır.

Diyabetik hastalarda diyet planlaması yapılırken diyetle alınan enerjinin ortalama \%45-65'i karbonhidrattan gelmesi önerilmektedir (Dworatzek, Arcudi, Gougeon, Husein, Sievenpiper ve Williams, 2013, s.37). Bu çalışmada

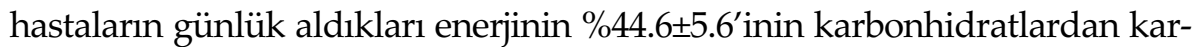
şlandığ1 saptanmıştır. Böbrek fonksiyonu normal olan diyabetli bireylerin genel popülasyona kıyasla daha fazla veya daha az protein alımını destekleyen veriler yetersizdir. Böbrek hastası olan diyabetli kişilerde, mikro veya makroalbüminüri, protein alımı için mevcut öneriler değişkenlik göstermektedir. Avrupa Diyabet Araştırmaları Birliği (EASD), kesin bir öneride bulunmak için yeterli kanıt bulunmadığını belirtirken, Kanada Diyabet Birliği (CDA) bir protein kısıtlamasının düşünülebileceğini belirtmektedir. Ancak Amerikan Diyabet Derneği (ADA), protein kıstlaması önermemektedir. Günlük alınan enerjinin \%15-20'i kadar protein alımı önerilmektedir (Ley, Hamdy, Mohan ve Hu, 2014, s.383). Bu çalışmadaki hastaların günlük protein alımları, önerilen değerler arasında olup toplam enerjinin \%17.1 \pm 2.4 'ünün proteinlerden sağlandığı bulunmuştur. Günlük yağ alım önerisi CDA tarafından alınan enerjinin \%20-35'i olarak belirtilirken, EASD alınan enerjinin \%35' inden az olması gerektiğini belirtmektedir (Ley, Hamdy, Mohan ve Hu, 2014, s.383). Diyabetli kişilerde koroner arter hastalığ1 riski diyabetli olmayanlara göre 2-3 kat daha fazladır. Bu yüzden doymuş yağ asidi alımı günlük alınan enerjinin \% 7 'sinin altında olmalı ve trans yağ asidi alımı minimumda tutulmalıdır (Dworatzek vd. (2013), s.37). Bu çalışmada diyabetli bireylerin günlük diyetle yağ tüketimi enerjinin $\% 38.1 \pm 4.9^{\prime}$ u kadardır ve önerilerin üzerindedir. Tüketilen DYA \%13.1 \pm 4.0 , MUFA \%13.4 \pm 3.4 , PUFA \%9.0 \pm 2.3 olarak 
saptanmıştır. Doymuş ve tekli doymamış yağ tüketiminin önerilen miktardan fazla olduğu görülmektedir. Diyabetli bireylere beslenme eğitimi verilirken günlük alınması gereken yağ miktarı kadar yağ türlerinin de üzerinde durulması hastaların kardiyovasküler hastalık riskini azaltmada fayda sağlayacaktır.

Burger vd. (2012)'nin diyabetli bireylerde diyet lifinin, karbonhidrat kalite ve miktarının ölüm riskine olan etkisini araştırdıkları çalışmada, diyet posanın tip 2 diyabetli hastaların tüm nedenlere bağlı ölüm riskleri ve kardiyovasküler hastalıklara bağlı ölüm riski ile diyet lifi tüketimi arasında ters orantı olduğu saptanmıştır. Diyetle günlük posa alım miktarı $25-50 \mathrm{~g}$ veya $14 \mathrm{~g} / 1000$ kkal olarak tavsiye edilmektedir (Dworatzek, Arcudi, Gougeon, Husein, Sievenpiper ve Williams, 2013, s.37). Bu araştırmadaki katılımcıların ise günlük posa tüketim miktarı önerilen miktarın altında olup 22.3 \pm 5.6 g olarak bulunmuştur (Tablo 1).

Araştırmaya katılan erkek ve kadınların SYİ puanları karşılaştırıldığında kadınların SYİ puanı ortalamasının $67.6 \pm 11.2$, erkeklerin ise $57.7 \pm 10.3$ olduğu görülmektedir (Tablo 2). Kadın katılımcıların \%7.3'ü kötü, \%89.5'i orta, \%3.2'si iyi SYİ puanına sahipken, erkeklerde bu oranlar sırasıyla \%16.6, \%80.8 ve \%2.6 şeklindedir. Akiş (2005)'in Ortadoğu Teknik Üniversite'sinde çalışan akademik personelin Sağlıklı Yeme İndekslerinin tespitine yönelik yaptığı çalışmada erkek katılımcıların \%27.4'ü kötü, \%68.0'i orta, \%4.6'sı iyi SYİ puanına sahipken, kadınlarda bu oranlar sirasıyla \%33.5, \%65.2 ve $\% 2.8$ olduğu bulunmuştur.

Çeşitli çalışmalar tip 2 DM hastalarında yeme bozukluğu ve yeme bozukluğu belirtilerinin artmış olduğunu göstermiştir (Sami vd. (2017), s.11). Herpetz vd.(2000)'in tip 2 diyabet hastası olan 321 kişinin katılımıla yaptıkları bir çalışmada, hastaların \% 81'inin kilolu ve obez olduğu tespit edilmiştir. Yeme bozuklukları prevalansı \%6.5-\%9 arasında olduğu görülmüş ve en yaygin yeme bozukluğunun tıkınırcasına yeme davranışı olduğu belirlenmiştir. BKİ ile yeme bozukluğu arasındaki ilişkini güçlü olduğu saptanırken, BKİ ile depresyon ve genel psikopatolojik değişkenler arasında zayıf bir ilişki bulunmuştur (Herpertz, Albus, Lichtblau, Köhle, Mann ve Senf, 2000, s.28). Van Strien, Herman ve Verheijden (2009)'nin 1342 kişi ile Hollanda'da yaptıkları yeme tutumları ile ilgili çalışmada da duygusal yeme ve dışsal yeme arasında güçlü bir ilişki saptanmıştır. Çalışmamızdaki DEBQ alt skorlarının kendi aralarındaki ilişkiye bakıldığında; bireylerin DEBQ kısıtlayıcı skorları ile DEBQ 
dışsal skorları arasında istatistiksel olarak anlamlı ilişki saptanmamıştır ( $p>0.05)$. Bireylerin DEBQ kısıtlayıc skorları ile duygusal skorları $(p<0.05)$ ve dışsal skorları ile duygusal skorları $(\mathrm{p}<0.05)$ arasında pozitif yönlü (kısıtlayıcı skor arttıkça duygusal skor artan ve dişsal skor arttıkça duygusal skor artan) istatistiksel olarak anlamlı ilişki saptanmıştır.

Araştırma bulgularına göre diyabetli bireyler ana ve ara öğünleri sıkça atlamaktadır. Bireylerin diyetle aldıkları günlük kalori ortalamasının yağdan gelen yüzdelik oranı önerilen miktarın üzerinde olduğu görülmektedir. Aynı şekilde tüketilen doymuş yağ oranı da önerilen miktarın üzerinde saptanmıştır. Tavsiye edilen günlük sodyum alım miktarının aşıldığı gözlenmiştir. Bireylerin günlük ortalama posa tüketim miktarı ise önerilen miktarın altında olduğu saptanmıştır. Bireylerin BKİ gruplarına göre DEBQ kısıtlayıcı ve duygusal yeme skor ortalamaları arasında istatistiksel olarak anlamlı farklılık bulunmamakla birlikte BKİ'si $25.0-29.9 \mathrm{~kg} / \mathrm{m} 2$ olan bireylerin DEBQ dışsal yeme skoru BKI'si 30.0-34.9 olan bireylerden istatistiksel olarak anlamlı düzeyde düşük bulunmuştur.

Tip 2 diyabet tedavisinde tıbbi beslenme tedavisi büyük önem taşımaktadır. Diyabetli hastalarda glisemik kontrolün sağlanması, mikro ve makrovasküler komplikasyonların önlenmesi için yeme bozuklukları ve beslenme alışkanlıkları düzeltilmeli, hastalara yaşam boyu davranış değiş̧ikliği kazandırılmalıdır. 
EXTENDED ABSTRACT

\title{
Determination of Nutritional Habits, Diet Quality and Eating Behaviors of Patients with Type 2 Diabetes
}

\author{
* \\ Elif Kaynarpunar - Mehmet Akman \\ Beykent Üniversitesi
}

Diabetes is a metabolic disease characterized by hyperglycemia resulting from defects in insulin secretion, activity, or both. The International Diabetes Federation (IDF) reports that the number of diabetes patients (type 1 and type 2), which was 285 million in 2009, increased to 425 million in 2017 and this projected to increase to 628.6 million by 2045 .

There are 3 main types of diabetes: type 1 diabetes, type 2 diabetes, and gestational diabetes. Type 2 Diabetes mellitus (Type $2 \mathrm{DM}$ ) is the most common form of DM characterized by hyperglycemia, insulin resistance and relative insulin deficiency. Type 2 diabetes is the most common type of diabetes all over the world, as well as it is an important chronic metabolic disease since it causes acute metabolic complications such as diabetic ketoacidosis, hypoglycemia-induced coma, long-term macrovascular complications (coronary heart disease, peripheral vascular disease, cerebrovascular disease) and microvascular complications (neuropathy, nephropathy, retinopathy). Although patients with type $2 \mathrm{DM}$ rarely need exogenous insulin, it may be necessary when blood glucose levels are not well controlled with either oral hypoglycemic drugs or diet alone. The link between diabetes and diet has been proven, and diet is just as important as medical interventions in the treatment of diabetes. Diet plays an important role in the therapeutic strategy for glycemic control and prevention of micro and macrovascular complications in patients with diabetes. The aim of this study is to evaluate the nutritional habits, diet quality and eating behaviors of patients with type 2 diabetes and to contribute to future studies.

The population of the study comprised people who applied to Kocaeli Darıca Farabi Training and Research Hospital, Nutrition and Diet Polyclinic between 01.April and 30.June.2018 and previously diagnosed with 
type 2 diabetes. Number of samples; Based on the number of 423 patients diagnosed with type 2 diabetes who applied to Kocaeli Darıca Farabi Training and Research Hospital Nutrition and Diet Polyclinic in 2017, it was calculated as 202 , with a $95 \%$ confidence interval. Systematic sampling was chosen as the sampling method.

The people who took part in this research was applied the questionnaire prepared by the researcher and the Dutch Eating Behavior Questionnaire (DEBQ) and Food Diversity Score and Healthy Eating Index -2005 (SYI) via face-to-face interview. In addition, 3-day food consumption record form was taken. While determining the portion sizes, "Picture Photo Catalogue" and food replica models were used. Nutrient Diversity Score and healthy nutrition index of SR were calculated according to food consumption records from individuals. Individuals' body weight was measured with Tanita BC 418 lightly clothed and without shoes.

The data got because of the research were analyzed using SPSS (Statistical Package for Social Sciences) 15.0 statistics package program. Nutrition Information System (BeBIS) 7.1 computer package program was used to evaluate the energy and nutrients that individuals take with their daily diet.

202 patients, 124 (61.4\%) female and 78 (38.6\%) male, took part in the study. $63.4 \%$ of the patients were overweight (BMI 25.0-29.9). $67.3 \%$ of the patients had diabetes in their first-degree relatives. The average duration of individuals with type 2 diabetes is 5.33 years. $57.9 \%$ of the patients use the oral anti-diabetic treatment method.

After learning that $59.4 \%$ of individuals have diabetes, their eating habits have changed and $55.4 \%$ eat their meals at certain times. $57.4 \%$ of the participants consume 2 main meals a day. When we look at the frequency of skipping the main meal; $14.9 \%$ never skip a main meal, $31.7 \%$ rarely, $36.6 \%$ occasionally, $16.8 \%$ often skip main meals. The most skipped main meal is lunch. In addition, $95.5 \%$ of the participants stated they skipped snacks.

When we look at the frequency of eating outside the home, it is seen that $4 \%$ of the participants eat outside the house every day, $27.7 \% 2-3$ times a month, $24.8 \%$ every $2-3$ months, and $7.9 \%$ never eat outside the home. Individuals mostly prefer kebap type foods to eat outside the home. 
Although $55.4 \%$ of the individuals participating in the study stated that they do not add salt to their meals, it is seen that the recommended daily sodium amount is exceeded when the dietary sodium intake is considered.

The most preferred oil type of the participants in their meals is olive oil $(45 \%)$, the most consumed type of bread is white bread $(57.9 \%)$, and the most used cooking method is boiled (37.1\%).

It was determined that women received $1522.4 \pm 332.19 \mathrm{kcal}$ and men $1846.4 \pm 373.22 \mathrm{kcal}$ with diet, and the difference between them was found to be statistically significant $(\mathrm{p}<0.05)$. It was determined that $44.6 \pm 5.6 \%$ of the daily energy intake comes from carbohydrates $(\mathrm{CHO}), 17.1 \pm 2.4 \%$ comes from proteins, and $38.1 \pm 4.9 \%$ comes from fats. Saturated fat (DF) consumed was $13.1 \pm 4 \%$, monounsaturated fat (MUFA) $13.4 \% \pm 3.4$, and polyunsaturated fat (PUFA) $9 \pm 2.3 \%$. The average daily fiber consumption amount is 22.3 grams. CHO (\%), Fat (\%), DYA(\%), MUFA(\%), PUFA(\%) and fiber consumption levels show statistically significant differences according to gender $(\mathrm{p}<0.05)$. Although the average amount of $\mathrm{CHO}(\%)$ and fiber consumed by men daily is statistically significantly higher than the average amount of $\mathrm{CHO}(\%)$ and fiber consumed by women daily; fat (\%), DYA(\%), MUFA(\%) and PUFA(\%) are statistically significantly less. There was no statistically significant difference between the mean protein (\%) consumption levels by gender ( $\mathrm{p}>0.05)$.

The SSI score was $67.64 \pm 11.27$ in females and $57.72 \pm 10.39$ in males. The mean SPI score of women was statistically significantly higher than the mean of men's SPI $(\mathrm{p}<0.05)$.

When the averages of 3-day food types consumed by the individuals taking part in the study are examined according to gender; The average of the type of food consumed by women is $9.05 \pm 1.49$, the average of the type of food consumed by men is $9.12 \pm 1$.24. There was no statistically significant difference between men and women in terms of the average number of food types ( $\mathrm{p}>0.05)$.

While the mean restrictive eating score of women was $2.72 \pm 0.72$, the mean of restrictive eating score of men was $2.09 \pm 0.54$. The restrictive eating score of female patients was statistically significantly higher than the restrictive eating score of male patients $(p=0.000 ; p<0.05)$. The mean emotional eating score of women was $2.37 \pm 0.71$ and the mean emotional eating 
score of men was $1.72 \pm 0.65$. There was no statistically significant difference between emotional eating scores of women and emotional eating scores of men ( $\mathrm{p}=0.000 ; \mathrm{p}>0.05)$; The emotional eating score of female patients was significantly higher than the emotional eating score of male patients. The mean external eating scores of women and men were $2.65 \pm 0.53$ and $2.66 \pm 0.50$, respectively. There was no statistically significant difference between external eating scores of women and external eating scores of men ( $\mathrm{p}>0.05)$.

Considering the evaluation of DEBQ restrictive eating score according to BMI groups; DEBQ restrictive eating score mean; $2.71 \pm 1.03$ in individuals with a BMI of $18.5-24.9 \mathrm{~kg} / \mathrm{m} 2$. It was found as $2.48 \pm 0.69$ in individuals with $25.0-29.9 \mathrm{~kg} / \mathrm{m} 2,2.34 \pm 0.71$ in individuals with $30.0-34.9 \mathrm{~kg} / \mathrm{m} 2$, $2.80 \pm 0.79$ in individuals with $35.9-39.9 \mathrm{~kg} / \mathrm{m} 2$, and $2.80 \pm 0.82$ in individuals with 40.0 and above. There was no statistically significant difference between the DEBQ restrictive eating score averages of individuals according to BMI groups ( $\mathrm{p}>0.05)$. DEBQ emotional eating score average; It is $2.54 \pm 0.92$ in individuals with a BMI of $18.5-24.9 \mathrm{~kg} / \mathrm{m} 2,2.10 \pm 0.75$ in individuals with a BMI of $25.0-29.9 \mathrm{~kg} / \mathrm{m} 2,2.06 \pm 0.76$ in individuals with a BMI of $30.0-34.9 \mathrm{~kg} / \mathrm{m} 2$, and $2.25 \pm 0.54$ in $35.9-39.9 \mathrm{~kg} / \mathrm{m} 2$. It was found to be $2.05 \pm 0.83$ in individuals with a score of 40.0 and above. There was no statistically significant difference between the DEBQ emotional eating score averages of individuals according to BMI groups ( $p>0.05$ ). DEBQ external eating score mean; Individuals with a BMI of $18.5-24.9 \mathrm{~kg} / \mathrm{m} 22.81 \pm 0.49$, individuals with a BMI of $25.0-29.9 \mathrm{~kg} / \mathrm{m} 22.57 \pm 0.49$, individuals with a BMI of $30.0-34.9 \mathrm{~kg} / \mathrm{m} 22.83 \pm 0.46,35.9-39.9 \mathrm{~kg} / \mathrm{m} 22.71 \pm 0.59,40.0$ It was found as $3.10 \pm 0.75$ in individuals with and above. There is a statistically significant difference between the DEBQ external eating score averages of individuals according to BMI groups $(\mathrm{p}=0.017 ; \mathrm{p}<0.05)$. According to the pair-wise comparisons made in order to determine the group that creates the difference; The DEBQ external eating score of individuals with a BMI of $25.0-29.9 \mathrm{~kg} / \mathrm{m} 2$ was found to be statistically significantly lower than those with a BMI of 30.0-34.9 ( $\mathrm{p}<0.05)$.

There was no statistically significant relationship between individuals' DEBQ restrictive scores and DEBQ extrinsic scores ( $p>0.05$ ). A statistically significant positive correlation was found between the individuals' DEBQ 
restrictive scores and emotional scores $(\mathrm{p}=0.000 ; \mathrm{p}<0.05)$, and between external scores and emotional scores $(\mathrm{p}=0.000 ; \mathrm{p}<0.05$. (As the limiting score increases, the emotional score increases and as the extrinsic score increases, the emotional score increases)

It was observed that $14.9 \%$ of the individuals taking part in our study did not skip the main meal, $31.7 \%$ rarely, $36.6 \%$ occasionally, $16.8 \%$ frequently skipped the main meal, and the most skipped main meal was lunch $(80.2 \%)$. In addition, it was determined that $95.5 \%$ of the individuals skipped snacks and the most frequently skipped snack was the mid-morning snack $(66.7 \%)$. According to the results of a study conducted between obese, diabetic, non-obese and non-diabetic groups, statistically significant differences were found between the groups when the main meal, the number of snacks, the status of skipping meals and the meals generally skipped $(p<0.05)$. In general, it was observed that all groups consumed three main meals a day, but especially the diabetic group (92.6\%) was the group that paid the most attention to three main-three snacks $(p<0.05)$. In the study conducted by Baban (2010), the rate of having three snacks was found to be $34 \%, 40 \%$ and $21.2 \%$ in the obese, diabetic and control groups, respectively.

Studies report that LDL-cholesterol levels and glucose intolerance are reduced by replacing saturated fatty acids with unsaturated fatty acids. In a meta-analysis study conducted with 15784 type 2 DM cases, a significant decrease in $\mathrm{HbA1c}$ and fasting plasma glucose was observed with olive oil supplementation in patients with type $2 \mathrm{DM}$ compared to the control group. When the oil used by the individuals taking part in our study were examined; It has been determined that $45 \%$ of the individuals use olive oil, $42.1 \%$ use sunflower oil, $3.5 \%$ corn oil, $1.5 \%$ hazelnut oil, $7.4 \%$ butter and $0.5 \%$ margarine.

According to a Canadian study, it was found that the risk of diabetes increases with the preference of oily cooking methods. In this study, when the most commonly used cooking methods were examined, it was determined that the participants mostly used boiling (37.1\%) and frying (22.8\%) the second most.

When making diet planning in diabetic patients, it is recommended that $45-65 \%$ of the energy taken from the diet should come from carbohydrates. In this study, it was determined that $44.6 \pm 5.6 \%$ of the daily energy 
intake of the patients was met from carbohydrates. There is insufficient data to support higher or lower protein intake in diabetic individuals with normal renal function compared to the general population. In people with diabetes who have kidney disease, micro or macroalbuminuria, current recommendations for protein intake vary. The European Association for Diabetes Research (EASD) states that there is insufficient evidence to make a firm recommendation, while the Canadian Diabetes Association (CDA) states that a protein restriction may be considered. However, the American Diabetes Association (ADA) does not recommend protein restriction. Protein intake is recommended as $15-20 \%$ of daily energy intake. The daily protein intakes of the patients in this study were within the recommended values, and it was found that $17.1 \% \pm 2.4 \%$ of the total energy was got from proteins. While the daily fat intake recommendation is specified by the CDA as $20-35 \%$ of the energy taken, the EASD states it should be less than $35 \%$ of the energy taken.

In a study investigating the effect of dietary fiber, carbohydrate quality and amount on the risk of death in individuals with diabetes, it was found that dietary fiber was inversely proportional to the risk of death from all causes and cardiovascular disease-related mortality in type 2 diabetes patients. Dietary fiber intake is recommended as $25-50 \mathrm{~g}$ or $14 \mathrm{~g} / 1000 \mathrm{kcal}$. The daily fiber consumption of the participants in this study was below the recommended amount and was found to be $22.3 \pm 5.6 \mathrm{~g}$.

When the SPI scores of the men and women taking part in the study are compared, it is seen that the mean SPI score of women is $67.6 \pm 11.2$, while that of men is $57.7 \pm 10.3$. While $7.3 \%$ of female participants had bad, $89.5 \%$ moderate and $3.2 \%$ good SPI scores, these rates for men were $16.6 \%$, $80.8 \%$ and $2.6 \%$, respectively. In the study conducted to determine the Healthy Eating Indices of the academic staff working at the Middle East Technical University, $27.4 \%$ of the male participants had bad, $68.0 \%$ of them had moderate and $4.6 \%$ of them had good SPI scores, while these rates for women were $33.5 \%, 65.2 \%$ and $2.8 \%$, respectively found to be.

Various studies have shown that patients with type 2 DM have increased symptoms of eating disorders and eating disorders. In a study conducted with the participation of 321 people with type 2 diabetes, it was determined that $81 \%$ of the patients were overweight and obese. The prevalence of eating disorders was found to be between $6.5 \%$ and $9 \%$, and the 
most common eating disorder was found to be binge eating. While the relationship between BMI and eating disorder was found to be strong, a weak relationship was found between BMI and depression and general psychopathological variables. In the study on eating attitudes conducted in the Netherlands with 1342 people, a strong relationship was found between emotional eating and external eating. When we look at the relationship between the DEBQ sub-scores in our study; No statistically significant correlation was found between the individuals' DEBQ restrictive scores and DEBQ extrinsic scores ( $p>0.05)$. A statistically significant relationship was found between the individuals' DEBQ restrictive scores and their emotional scores $(\mathrm{p}<0.05)$, and between their external scores and their emotional scores $(\mathrm{p}<0.05)$, with a positive (emotional score increasing as the restrictive score increased and emotional score increasing as the external score increased).

According to research findings, individuals with diabetes often skip main and snack meals. It is seen that the average daily calorie intake of individuals with the diet, the percentage of fat from the diet is above the recommended amount. Likewise, the amount of saturated fat consumed was found to be above the recommended amount. It has been observed that the recommended daily sodium intake is exceeded. It has been determined that the daily average fiber consumption amount of individuals is below the recommended amount. Although there is no statistically significant difference between the mean DEBQ restrictive and emotional eating scores according to the BMI groups of the individuals, the DEBQ extrinsic eating score of the individuals with a BMI of $25.0-29.9 \mathrm{~kg} / \mathrm{m} 2$ is statistically significant compared to the individuals with a BMI of 30.0-34.9. level was low.

Medical nutrition therapy is of great importance in the treatment of type 2 diabetes. Eating disorders and nutritional habits should be corrected in order to provide glycemic control and prevent micro and macrovascular complications in patients with diabetes, and patients should be provided with lifelong behavioral changes. 


\section{Kaynakça / References}

Akiş C. (2005). Ortadoğu Teknik Üniversitesi'nde görevli akademik personelin diyet örüntüleri, diyet kalite indeksleri ve sağhlkh yeme indekslerinin belirlenmesi üzerine bir çalışma. Yüksek lisans tezi. Hacettepe Üniversitesi, Sağlık Bilimleri Enstitüsü, Beslenme ve Diyetetik Anabilim Dalı, Ankara.

American Diabetes Association. (2014). Diagnosis and classification of diabetes mellitus. Diabetes Care, 37, 81-90.

Baban, M. (2010). Obez ve diyabetik yetişkinlerin beslenme bilgi düzeyleri, beslenme alışkanlıkları, diyet ve diyabetik ürünleri algılama düzeylerinin karşılaştırmalı olarak değerlendirilmesi. Yüksek lisans tezi. İstanbul Üniversitesi, Sağlık bilimleri Enstitüsü, İç Hastalıkları Ana Bilim Dalı, İstanbul.

Burger, KN., Beulens, JW., van der Schouw, YT., Sluijs, I., Spijkerman, AM., Sluik, D, and Nöthlings, U. (2012). Dietary fiber, carbohydrate quality and quantity, and mortality risk of individuals with diabetes mellitus. https://doi.org/10.1371/journal.pone.0025955 adresinden erişildi.

Çobanoğlu, Z., Altuntaş, Y., Karamustafalığlu, KO., Şengül, A. ve Çobanoğlu, N. (2008). Tip 1 ve tip 2 diyabetes mellitus hastalarında yeme bozuklukları ve bozulmuş yeme davranışı. Düşünen Adam, 21(1-4), 24-31.

Dworatzek, PD., Arcudi, K., Gougeon, R., Husein, N., Sievenpiper, JL. and Williams, SL. (2013). Nutrition therapy. Canadian Journal of Diabetes, 37(1), 45-55.

Erhardt, DJ. (2010). Beslenme bilgi sistemi (BeBIS) 7,1. Stuttgart, Almanya: Hohenheim Üniversitesi.

Forbes, JM. and Cooper, ME. (2013). Mechanisms of diabetic complications. American Physiological Society, 93, 137-188.

Herpertz, S., Albus, C., Lichtblau, K., Köhle, K., Mann, K. and Senf, W. (2000). Relationship of weight and eating disorders in type 2 diabetic patients: a multicenter study. International Journal of Eating Disorders, 28(1), 68-77.

International Diabetes Federation. (2017). IDF Diabetes Atlas, 8th ed, Brussels, Belgium.

Ley, SH., Hamdy, O., Mohan, V. and Hu, FB. (2014). Prevention and management of type 2 diabetes: Dietary components and nutritional strategies. Lancet, 383 (9933).

Mann, JI., De Leeuw, I., Hermansen, K., Karamanos, B., Karlström, B., Katsilambros, N. and Vessby, B. (2004). Diabetes and Nutrition Study Group (DNSG) of the European Association: Evidence-based nutritional approaches to the treatment and prevention of diabetes mellitus. Nutrition Metabolism $\mathcal{E}$ Cardiovascular Diseases Journal, 14(6), 373-394. 
Morris, E., Aveyard, P., Dyson, P., Noreik, M., Bailey, C., Fox, R. and Jebb, SA. (2018). Dietary approaches to the management of type 2 diabetes (DIAMOND): protocol for a randomised feasibility trial. http://dx.doi.org/0.1136/bmjopen2018-026460 adresinden erişildi.

Morris, S. and Wylie-Rosett, J. (2010). Medical nutrition therapy: A key to diabetes management and prevention. Clinical Diabetes Journals, 28(1), 12-17.

Olokoba, AB., Obateru, OA. and Olokoba, LB. (2012). Type 2 diabetes mellitus: A review of current trends. Oman Medical Journal, 27(4), 269-273.

Özdemir, İ. ve Hocaoğlu, Ç. (2009). Tip 2 diabetes mellitus ve yaşam kalitesi: Bir gözden geçirme. Göztepe Tıp Dergisi, 24(2), 73-78.

Rakıcıoğlu, N., Tek, N., Ayaz, A. ve Pekcan, G. (2012). Yemek ve besin fotoğraf kataloğu, ölçü ve miktarlar. Ankara: Hacettepe Üniversitesi Yayınları.

Rivellese, AA., Boemi, M., Cavalot, F., Costagliola, L., De Feo, P., Miccoli, R. and Zavaroni, I. (2008). Dietary habits in type II diabetes mellitus: How is adherence to dietary recommendations?. European Journal of Clinical Nutrition, 62(5), 660-664.

Saeedi, P., Petersohn, I., Salpea, P., Malanda, B., Karuranga, S., Unwin, N. and Williams, R. (2019). Global and regional diabetes prevalence estimates for 2019 and projections for 2030 and 2045: Results from the International Diabetes Federation Diabetes Atlas, 9th edition. Diabetes Research And Clinical Practice, 157, 107-843.

Sami, W., Ansari, T., Butt, NS. and Hamid, MR. (2017). Effect of diet on type 2 diabetes mellitus: A review. International Journal Health Sciences (Qassim University), 11(2), 65-71.

Schwingshackl, L., Lampousi, A., Lampousi, M., Portillo, MP., Romaguera, D., Hoffmann, G. and Boeing, H. (2017). Olive oil in the prevention and management of type 2 diabetes mellitus: A systematic review and meta-analysis of cohort studies and intervention trials. Nutrition E Diabetes journal, 7(4), 262.

Van Strien, T., Herman, CP. and Verheijden, MW. (2009). Eating style, overeating and overweight in a representative Dutch sample. Appetite, 52, 380-387.

Wu, Y., Ding, Y., Tanaka, Y. and Zhang, W. (2014). Risk factors contributing to type 2 diabetes and recent advances in the treatment and prevention. International Journal of Medical Sciences, 11(11), 1185-1200. 


\section{Kaynakça Bilgisi / Citation Information}

Kaynarpunar, E. ve Akman, M. (2021). Tip 2 diyabetli hastaların beslenme alışkanlıkları, diyet kalitesi ve yeme davranışlarının değerlendirilmesi. OPUS-Uluslararası Toplum Araştırmaları Dergisi, 18(40), 2615-2637. DOI: 10.26466/opus.857147. 